\title{
Spirulina Reverses Histomorphological Changes in Diabetic Osteoporosis in Pioglitazone Treated Rats
}

\author{
Chauhan Devesh¹, Mehla Kritika1, Nair Anroop², Sehajpal Prabodh Kumar ${ }^{3}$ and Gupta Sumeet ${ }^{1 *}$
}

${ }^{1}$ Department of Pharmacology, M. M. College of Pharmacy, M. M. University, Mullana, Haryana, India

${ }^{2}$ Department of Pharmaceutics, M. M. College of Pharmacy, M. M. University, Mullana, Haryana, India

${ }^{3}$ Department of Molecular Biology and Biochemistry, Guru Nanak Dev University, Amritsar, Punjab, India

\begin{abstract}
Aim: The study was undertaken to assess the protective effect of Spirulina fusiform on risk fracture of bone in insulin resistance rat model and pharmacodynamics effects of Pioglitazone with Spirulina in treating hyperglycemia and hyperlipidaemia of insulin resistance rat.
\end{abstract}

Method: For this aim, 30 Wistar albino rats were equally divided into five groups as control (NC), diabetes mellitus (DM), diabetes mellitus + Pioglitazone $(D M+P)$, diabetes mellitus + Spirulina $(D M+S)$, and diabetes mellitus + Pioglitazone + Spirulina (DM+P+S). Serum glucose, Triglyceride, HDL, LDL and insulin concentrations were estimated by standard methods in blood samples collected on 21st day. Morphological changes in pancreas and microarchitectual structure in femur bone were observed by histopathology studies.

Results: A significant decrease in bone thickness was observed in Diabetes Mellitus rats group $(p<0.001)$ when compared to $\mathrm{DM}+\mathrm{P}+\mathrm{S}$. In Pioglitazone with Spirulina treated group, the results demonstrated that the trabeculae bone thickness restored to original position and showed better restoration of beta cell in comparison to Spirulina treated and Pioglitazone treated group. The intactness and integrity of the bone surface as well as the bone strength also improved. Besides, chromium and gamma-linoleic acid in Spirulina helped to decrease the fasting serum glucose, HDL, LDL and triglycerides levels in insulin resistance rats.

Conclusion: These findings suggest that combination therapy of Pioglitazone with Spirulina reduced the risk of fracture in insulin resistance rats. Additionally, Spirulina complemented the anti hyperglycemic and anti lipidemic activity of Pioglitazone.

Keywords: Spirulina; Insulin resistance; Diabetes osteoporosis

\section{Introduction}

Osteoporosis is a common disorder that affects around 2000 million peoples worldwide [1]. Insulinopenia in type 1 diabetes (T1DM) or resistance to the metabolic actions of insulin in type 2 diabetes (T2DM), are both associated with bone loss leads to diabetic osteoporosis. Skeletal defects that are observed in conjunction with Type 1 Diabetes Mellitus due to diminished linear bone growth, lead to increased risk of osteoporosis [2]. In contrast, Bone loss appears to be more rapid in patients with Type 2 Diabetes Mellitus [3]. It is a systemic skeletal diseases characterized by low bone mass due to micro architectural deterioration of bone tissue with consequent increase in bone fragility and susceptibility to fractures. The loss and deterioration of the structure of bone tissue is caused by a net imbalance in bone remodeling, due to either to an increase activity of osteoclasts and decrease activity of osteoblasts [4]. About $70 \%$ of variations in fracture risk associated with diabetes can be attributed to genetic differences [5-7]. Bone loss has been observed to be greater in patients with poorly controlled diabetes than in those whose diabetes is in good control $[8,9]$.

A number of therapeutic agents exist for the treatment of Type 2 Diabetes Mellitus, including metformin, sulfonylurea, di-PeptylPeptidase-4 inhibitors, PPAR agonists, a-glucosidase inhibitors, insulin, and glucagon like peptide- 1 analogs. Despite adequate efficacy and durability, some of these agents suffer from liabilities, including hypoglycemia, weight gain, edema, bone fractures, lactic acidosis, and gastrointestinal intolerance [10]. Thiazolidinedione (TZDs) are one of the latest new drug therapies for type 2 Diabetes Mellitus. They are ligands for Peroxisome Proliferator activated receptor- $\gamma$ (PPAR $\gamma)$, a family of nuclear receptors that regulate gene transcription. The PPAR- $\gamma 1$ isoform is expressed in many cell types, including adipocytes, osteoblasts, muscle cells and macrophages, whereas PPAR- $\gamma 2$ expression is restricted primarily to adipose cells and is absolutely necessary for fat development in mice. The flow of mesenchymal precursor cells from osteoblastic to adipogenic lineages is mediated by PPAR $\gamma$. This effect led to reduced bone formation and loss of bone density [11]. Thiazolidinediones also have anti-tumour activity because of expression of PPAR- $\gamma$ receptor in neoplastic cell line of colon, breast, pancreas and prostate. Studies in rodents have shown that PPAR agonists can potentiate tumorigensis, and are multispecies, multisex carcinogens $[12,13]$. But this in vitro data, it was not reflected in human trials with colorectal and prostatic carcinoma. Rather in murine models, this drug showed some tumour inducing activity and hence they should be avoided in patients with adenomatous polyposis coli. Confirmed human data regarding the cancer risk associated with thiazolidinedione are not available [14]. So European Medicine Agency recommended it should be investigated in longitudinal study

*Corresponding author: Sumeet Gupta, Associate Professor, Department of Pharmacology, M. M. College of Pharmacy, M. M. University, Mullana, (Ambala), Haryana, India, Tel: +91 9872620252, +918059930156; E-mail: sumeetgupta25@ gmail.com

Received December 08, 2011; Accepted April 30, 2012; Published May 05, 2012

Citation: Devesh C, Kritika M, Anroop N, Kumar SP, Sumeet G (2012) Spirulina Reverses Histomorphological Changes in Diabetic Osteoporosis in Pioglitazone Treated Rats. J Diabetes Metab S1:006. doi:10.4172/2155-6156.S1-006

Copyright: @ 2012 Devesh C, et al. This is an open-access article distributed unde the terms of the Creative Commons Attribution License, which permits unrestricted use, distribution, and reproduction in any medium, provided the original author and source are credited. 
specially those diabetic patients who are more than 40 yrs of age [15]. The clinical development of TZDs was initially delayed because of poor efficacy or un-acceptable toxicity, which led to discontinuation of ciglitazone and englitazone after the phase II clinical trials [16]. A small study was conducted with troglitazone, the first available thiazolidinedione in diabetic patients for 1 year suggested the bone mineral density was increased. This study was limited in that there was no control group and variations in bone mineral density among the treated patients was sufficient to raise questions about the overall effect. Furthermore, troglitazone has been withdrawn from the market because of hepatotoxicty. Till date there are many reports published on serious adverse effect of thiazolidinedione on bones of Type 2 Diabetes Mellitus in animal model $[17,18]$. In aggregate, there is a pressing need to develop novel modalities for the treatment of diabetes to stem the spread of this global epidemic.

Serious side effects of diseases as well as medicines are dangerous to patient community. Management of diabetes without any side effects of drugs and complication of disease is still a challenge to the medical fraternity. There is continuous search for alternative drugs. Therefore, it is prudent to look for options in herbal medicine for diabetes as well. From an ethno pharmacological perspective, it is important to understand that this disease is at the interface of conventional biomedical and local (or traditional) treatment. There is one recent report published in the prevention of serious adverse effect of rosiglitazone on bones of Type 2 Diabetes Mellitus in animal model [18].

Specific marine plants have been attracting attention for their ability to improve bone metabolism, since they are rich in minerals and growth factors. Spirulina fusiform, a filamentous and unicellular alga is a cynobacterium belonging to the Oscillatoraceae family that usually grows in the alkaline waters of Africa, Asia, North and South America. Spirulina represents one of the richest sources of plant protein (60$70 \%)$ and is also a good source of vitamins specially vitamin $B_{12}$ and provitamin A ( $\beta$-carotene), and minerals like calcium, chromium and magnesium. It is also one of the few sources of dietary $\gamma$-linoleic acid (GLA) and contains a host of other phytochemicals that have potential health benefits [19]. Spirulina is gaining more attention from medical scientists as a nutraceutical and source of potential pharmaceuticals.

At this point only few activity of spirulina has been evaluated on animal models. Keeping in view the pharmacological properties of $S$. fusiform, present investigation was undertaken to assess the protective effect of $S$. fusiform on a risk fracture of bone in insulin resistance rat model.

\section{Materials and Methods}

\section{Animals}

Adult male albino Wistar rats weighing about 180-200 g were used with the approval of the Institute Animal Ethics Committee (MMCP/ IEC/10/01). The animals were housed under standard conditions of temperature $\left(24-28^{\circ} \mathrm{C}\right)$ and relative humidity $(60-70 \%)$ with a $12: 12$ light-dark cycle. The animals were fed with standard pellet diet (Lipton India, Ltd) and water ad-libitum.

Spirulina fusiformis: Spirulina fusiformis in the form of powder was obtained from RECON Ltd., (Bangaluru, India). It was suspended in vehicle (olive oil) and was given to each mouse by oral gavage daily.

\section{Drugs}

Dexamethasone sodium phosphate was obtained as a gift from
M/s. Strides Arcolabs, (Bangalore, India) and Pioglitazone maleate from Torrent Pharmaceutical Ltd, (Ahmedabad, Gujarat).

\section{Experimental design}

Dexamethasone-induced insulin resistance model [20]: Animals were divided into following 5 groups. Each consisting of 9 rats:

Group 1: Normal control rats (NC) -- Oral saline

Group 2: Diabetic control rats- Dexamethasone sodium phosphate (10 $\mathrm{mg} / \mathrm{kg}$, once daily, s.c.) (DM)

Group 3: Diabetic control rats + Pioglitazone $(10 \mathrm{mg} / \mathrm{kg}$ b.w/day in one dose per oral) $(\mathrm{DM}+\mathrm{P})$

Group 4: Diabetic control rats + Spirulina $(500 \mathrm{mg} / \mathrm{kg}$ b.w/day in two divided doses per oral) $(\mathrm{DM}+\mathrm{S})$

Group 5: Diabetic control rats + Spirulina $(500 \mathrm{mg} / \mathrm{kg}$ b.w/day in two divided doses per oral $)+$ Pioglitazone $(10 \mathrm{mg} / \mathrm{kg} \mathrm{B.w} /$ day in one dose per oral) $(\mathrm{DM}+\mathrm{P}+\mathrm{S})$

In groups 2-5, Insulin resistance (IR) was induced in male rats aged 8 weeks by the daily injection of dexamethasone $(10 \mathrm{mg} / \mathrm{kg} \mathrm{s.c.}$.) for seven days. The dose of dexamethasone is based on preliminary work which showed that insulin tolerance is induced within a week and it was confirmed at $3^{\text {rd }}$ day by homeostasis model assessment (HOMAIR) calculated by following formula: HOMA-IR = fasting insulin $(\mu \mathrm{U} /$ $\mathrm{ml}) \mathrm{x}$ fasting glucose $(\mathrm{mmol} / 1) / 22.5$.

After treatment for seven days insulin resistance was identified using the tolbutamide $(10 \mathrm{mg} / \mathrm{kg})$ which failed to lower the hyperglycemic levels. Rats with insulin resistance were employed as the model of noninsulin dependent diabetes mellitus. All the animals received their respective assigned treatment daily for a period of 21 days. Among each group three rats were sacrificed for histology of pancreas and remaining continued for 45 days treatment for another parameters.

\section{Biochemical estimations}

Blood samples were drawn at weekly intervals on the day 7,14 , 21 the animals were anesthetized with ether, and blood was collected from retro-orbital puncture. About $30 \mu \mathrm{l}$ serum was then separated for the estimation of Glucose [21], Triglyceride [22], HDL [23] LDL [24], adiponectin levels [25] (Rat adiponectin ELISA kit; Linco Research Inc.) and serum insulin was estimated by radio immuno assay kit purchased from Stat Diagnostics (Linco Research Inc.), Mumbai, India. All other reagents and chemicals used in the study were of analytical grade. All drugs were dissolved in distilled water for oral administration.

For histology of pancreas: Three animals from each group were sacrificed under anesthesia by pentobarbitone sodium $(60 \mathrm{mg} / \mathrm{kg})$; the pancreas were removed, cut into small fragments and fixed overnight, in freshly prepared Zamboni's fixative. Representative fragments were always taken from the tail of the pancreas. They were dehydrated in ethanol series, cleared in xylene and embedded in paraffin. Section of $7 \mu \mathrm{m}$ thickness were cut on a microtome and transferred onto microscopic slides which were dried at $55^{\circ} \mathrm{C}$ for $30 \mathrm{~min}$ to enhance section attachment.

For histology of bone: After 45 days treatment, animals from each group were sacrificed under anesthesia by pentobarbitone sodium $(60$ $\mathrm{mg} / \mathrm{kg}$ ); the bones were dissected out and tissue section washed on ice cold saline immediately. A portion of tissue was fixed in $10 \%$ neutral formalin fixative solution for histological studies. After fixation tissues were embedded in paraffin, solid sections were cut at $5 \mu \mathrm{m}$ and the sections were stained with haematoxylin and eosin [26]. 
Citation: Devesh C, Kritika M, Anroop N, Kumar SP, Sumeet G (2012) Spirulina Reverses Histomorphological Changes in Diabetic Osteoporosis in Pioglitazone Treated Rats. J Diabetes Metab S1:006. doi:10.4172/2155-6156.S1-006

Page 3 of 7

For scanning electronic microscopy: After 45 days treatment, the animals were sacrificed under anesthesia; the femoral bone was examined for bone intactness, integrity and micro hardness using Scanning Electron Microscopy (SEM) (JFC-1100E, JEOL Co, Japan).

\section{Statistical analysis}

The data were expressed as mean \pm SEM. The statistical significance between means was analyzed using one-way analysis of variance (ANOVA) followed by Tukey's multiple comparison test. A $\mathrm{p}<0.05$ was considered as statistically significant.

\section{Results}

The serum glucose level of more than $300 \mathrm{mg} / \mathrm{dl}$ were found insulin resistance after administration of dexamethasone $(10 \mathrm{mg} / \mathrm{kg}$, s.c.) for seven days and confirmed by homeostasis model assessment (HOMAIR) as shown in table 1 and the treatments were started for 3 weeks. At the end of $3^{\text {rd }}$ week, Pioglitazone and Pioglitazone with Spirulina treated groups showed a highly statistical significant $(\mathrm{P}<0.0001)$ decrease in serum glucose level when compared to that of diabetic control group. Pioglitazone treated group alone also showed decrease but was much less significant $(p<0.001)$ as shown in Table 2. Six weeks of daily treatment in combination of spirulina with Pioglitazone led to a dose-dependent fall in serum sugar levels up to $80 \%$ and affectivity remain constant up to $45^{\text {th }}$ day. Quite evidently the combined therapy of
Pioglitazone with spirulina showed highly beneficial results in treating insulin resistance induced hyperglycemia.

Pioglitazone alone and Pioglitazone with spirulina led to statistically significant $(\mathrm{P}<0.0001)$ decrease in serum triglycerides and serum LDL levels, when compared to diabetic control group (Table 3 ). At the end of $3^{\text {rd }}$ week of treatment, the spirulina alone treated group showed less reduction in LDL and triglycerides levels compared to diabetic group. Interestingly the decrease in the HDL levels was significant in rats treated with Pioglitazone with spirulina and failed to show similar decrease in rest of the groups.

The level of serum insulin increased during insulin resistance when compared to normal group, however, administration of Spirulina with Pioglitazone brought levels back to near normal values compared to diabetic control group which had statistically significantly higher levels $(\mathrm{P}<0.0001)$. The adiponectin levels significantly $(\mathrm{p}<0.0001)$ increases in combination of pioglitazone with Spirulina when compared to diabetic control group which seems to be increase insulin sensitivity.

\section{Histomorphology of pancreas}

In Figure 1 plate 1 group A, the cells of the pancreas were all present in their normal proportions. The acinar cells which stained strongly are arranged in lobules with prominent nuclei. The islets cells are seen embedded within the acinar cells and surrounded by fine capsule. In

\begin{tabular}{|c|c|c|c|}
\hline Groups & Fasting glucose (mmol/l) & Fasting insulin $(\mu \mathrm{U} / \mathrm{ml})$ & HOMA-IR \\
\hline Normal Control & $4.61 \pm 4.2$ & $15.01 \pm 3.1$ & $3.07 \pm 3.6$ \\
\hline Positive Control (DM) & $20.43 \pm 3.4$ & $25.19 \pm 6.5$ & $22.87 \pm 8.3$ \\
\hline DM + Pioglitazone & $12.71 \pm 2.8^{* *}$ & $19.04 \pm 1.0^{*}$ & $10.75 \pm 4.2^{\star \star *}$ \\
\hline DM + Spirulina & $16.71 \pm 2.5^{*}$ & $23.18 \pm 3.8^{\mathrm{ns}}$ & $17.21 \pm 5.5^{\mathrm{ns}}$ \\
\hline DM + Pioglitazone+ Spirulina & $11.78 \pm 4.9^{* *}$ & $13.25 \pm 2.2^{\star * \star}$ & $6.9 \pm 1.2^{* * *}$ \\
\hline
\end{tabular}

Table 1: Confirmation of insulin resistance after induction of dexamethasone in rat model.

\begin{tabular}{|c|c|c|c|c|c|}
\hline \multirow{2}{*}{\multicolumn{2}{|c|}{ Groups $(n=6)$}} & \multicolumn{4}{|c|}{ Serum Glucose Level (mg/dl) } \\
\hline & & \multirow{2}{*}{\begin{tabular}{|l|} 
O day \\
$85.43 \pm 12.48$ \\
\end{tabular}} & \multirow{2}{*}{$\begin{array}{l}7^{\text {th }} \text { day } \\
86.19 \pm 17.19\end{array}$} & \multirow{2}{*}{\begin{tabular}{|l|}
$1^{\text {th }}$ day \\
$81.74 \pm 20.11$
\end{tabular}} & \multirow{2}{*}{$\begin{array}{l}\mathbf{2 1}^{\text {st }} \text { day } \\
89.76^{\star \star *} \pm 2.63\end{array}$} \\
\hline 1. & Normal Control & & & & \\
\hline 2. & Positive Control (DM) & $348.23 \pm 14.4$ & $363.48 \pm 12.1$ & $372.31 \pm 4.3$ & $379.20 \pm 21.3$ \\
\hline 3. & DM + Pioglitazone & $332.17 \pm 29.1$ & $202.31 \pm 9.3$ & $143.21 \pm 10.4$ & $91.34^{* * *} \pm 6.93$ \\
\hline 4. & DM + Spirulina & $338.14 \pm 7.9$ & $302 \pm 9.36$ & $289.17 \pm 21.2$ & $342.16^{* *} \pm 24.18$ \\
\hline 5. & DM + Pioglitazone+ Spirulina & $320.78 \pm 11.29$ & $221.77 \pm 14.9$ & $173.11 \pm 12.0$ & $75.70^{* * *} \pm 3.4$ \\
\hline
\end{tabular}

Values are given as mean \pm SEM for groups of six animals each

Normal group (Normal saline)

Diabetic control group (Dexamethasone)

${ }^{* * *}$ Values are extremely significant on $21^{\text {st }}$ day at ${ }^{* * *} p<0.0001$ (Tukey $t$-test). Diabetic control group were compared with normal group. Spirulina and Pioglitazone with spirulina groups were compared with diabetic control

Table 2: Effect of Pioglitazone and Spirulina on Serum Glucose level at $21^{\text {st }}$ day in Insulin Resistant Rat Model.

\begin{tabular}{|c|c|c|c|c|c|c|}
\hline \multirow{2}{*}{\multicolumn{2}{|c|}{$\begin{array}{l}\text { Groups } \\
(n=6)\end{array}$}} & \multicolumn{4}{|c|}{ Serum lipid Profile (mg/dl) } & \multirow{3}{*}{$\begin{array}{l}\text { Adiponectin levels (ng/dl) } \\
7.03^{\star \star \star} \pm 2.03\end{array}$} \\
\hline & & \multirow{2}{*}{$\begin{array}{l}\text { HDL } \\
32.11^{\text {(ns) }} \pm 21.7\end{array}$} & \multirow{2}{*}{$\begin{array}{l}\text { Triglycerides } \\
87.33^{\star \star *} \pm 2.2\end{array}$} & \multirow{2}{*}{$\begin{array}{l}\text { LDL } \\
90.29^{\star * *} \pm 12.7\end{array}$} & \multirow{2}{*}{$\begin{array}{l}\begin{array}{l}\text { Insulin Level } \\
(\mu \mathrm{g} / \mathrm{ml})\end{array} \\
16.03^{\star * *} \pm 0.74 \\
\end{array}$} & \\
\hline 1. & Normal Control & & & & & \\
\hline 2. & Positive Control (DM) & $20.40 \pm 13.7$ & $211.32 \pm 16.3$ & $191.78 \pm 26.2$ & $24.87 \pm 0.48$ & $1.96 \pm 0.43$ \\
\hline 3. & DM + Pioglitazone & $45.77^{\text {(ns) }} \pm 17.3$ & $110.7^{\star * *} \pm 4.50$ & $70.31^{\star * *} \pm 23.7$ & $18.03^{\star * *} \pm 0.23$ & $5.32^{* * *} \pm 0.87$ \\
\hline 4. & DM + Spirulina & $38.57^{(\mathrm{ns})} \pm 19.99$ & $175.45^{\star \star} \pm 25.45$ & $115^{\star \star} \pm 27.3$ & $23.56^{* *} \pm 0.60$ & $4.04^{* \star *} \pm 0.31$ \\
\hline 5. & DM + Pioglitazone + Spirulina & $57.4^{*} \pm 23.7$ & $91.12^{\star \star *} \pm 12.2$ & $89.31^{\star * \star} \pm 06.7$ & $14.33^{\star \star *} \pm 0.27$ & $6.80^{* * *} \pm 1.2$ \\
\hline
\end{tabular}

Values are given as mean \pm SEM for groups of six animals each

Normal group (Normal saline)

Diabetic control group (Dexamethasone)

${ }^{* * *}$ Values are extremely significant on $21^{\text {st }}$ day at ${ }^{* * *} p<0.0001$ (Tukey $t$-test). Diabetic control group were compared with normal group. Spirulina and Pioglitazone with spirulina groups were compared with diabetic control

Table 3: Effect of Pioglitazone and Spirulina on serum lipid profile at $21^{\text {st }}$ day in insulin resistance rat model. 
Citation: Devesh C, Kritika M, Anroop N, Kumar SP, Sumeet G (2012) Spirulina Reverses Histomorphological Changes in Diabetic Osteoporosis in Pioglitazone Treated Rats. J Diabetes Metab S1:006. doi:10.4172/2155-6156.S1-006

plate 2 Group B, The acinar cells around the islets through seem to be in normal proportion does not look classical. The islets were damaged, shrunken in size and infiltration of lymphocytes was observed. In plate 3 group C, the size of cell and number of beta cells were back in normal position after 21 days treatment of Pioglitazone alone. The islet cells were compactly arranged, with negligible intercellular space. In plate 4 Group D in Spirulina treated group, the islets cells are seen in few numbers. The size of the cell is shrunken with architectural disarray and hydrolyses also when compared to diabetic control group. In plate 5 group E, the islets proportionate are comparatively better as compared to positive control group. Spirulina with Pioglitazone show better restoration of beta cell in comparison of Spirulina treated and Pioglitazone treated group.

\section{Histomorphometric changes of femur bone}

In Figure 2 Plate 1 Group A shows the Photograph of the middle shaft of the femur bone of a normal rat showing the normal architecture (Trabeculae) of the bone mass. The Peritoneum (P), the Endosteum (E) and a number of canals are observed carrying the blood vessels and nerves, Harversian canals ( $\mathrm{H}$ arrow). A higher magnification of the previous section showing the bone cells (osteocytes) in lacunae, the old cells appear spindle in shape with oval flattened nuclei $(\mathrm{O})$ while the young cells appear more rounded with rounded nuclei (arrow). In plate 2 Group B, A Photograph of the middle shaft of the femur bone of a rat treated with dexamethasone administration induces insulin resistance, showing destruction of medullary cavity at the expense of the bone tissue thickness and Haversian canals forming gaps (g) within the bone tissue. Both the outer and the inner surfaces of the bone tissue show areas of invasion (arrow head) and irregularities (wavy arrow) especially at the inner surface. A higher magnification of the previous section shows areas of invasion of bone tissue containing multinucleated cells (arrow). In plate 3 group C, A Photomicrograph of the middle shaft of the femur bone of a rat treated with the Pioglitazone only showing both surfaces of bone tissue are regular (arrow head). The Harversian canals (arrow) are to be normal in size. A higher magnification of the previous section shows normal sized Haversian canals (h) and regular arrangement of the lamellae of the matrix. Old osteocytes (arrow) are located at the center of the bone tissue, while the young ones are located more peripherally (arrow head). In Plate 4 group D, A Photograph of the middle shaft of the femur bone of a rat treated with spirulina showing both the inner and the outer surfaces of the bone tissue still become irregular but very less compare to Pioglitazone (arrow head) especially the outermost one. A higher magnification showing some of the Haversian canals are normal in size while others are markedly dilated (arrow head). The old osteocytes are located in the center of the bone tissue (arrow head), while the young ones are located more peripherally but in an abnormal arrangement denoting incomplete regeneration of bone tissue. In plate 5 group $\mathrm{E}, \mathrm{A}$ Photomicrograph of the middle shaft of the femur bone of a rat treated Pioglitazone with Spirulina only showing both surfaces of bone tissue are regular (arrow head). The Harversian canals (arrow) are too normal in size. A Higher magnification of the previous section showing normal sized Haversian canals $(\mathrm{H})$ and regular arrangement of the lamellae of the matrix. Old osteocytes (arrow) are located at the center of the bone tissue, while the young ones are located more peripherally (arrow head). The trabeculae thickness is in normal position due to collagen fiber content deposited. The trabeculae thickness of femur bone in combination of Pioglitazone with spirulina treated group were found to be $(7 \mathrm{~mm} \pm 0.7)$ compared to diabetic control group (4.6 $\mathrm{mm} \pm 1.5)$, the results was statistically significant $(\mathrm{P}<0.001)$ but when we compare
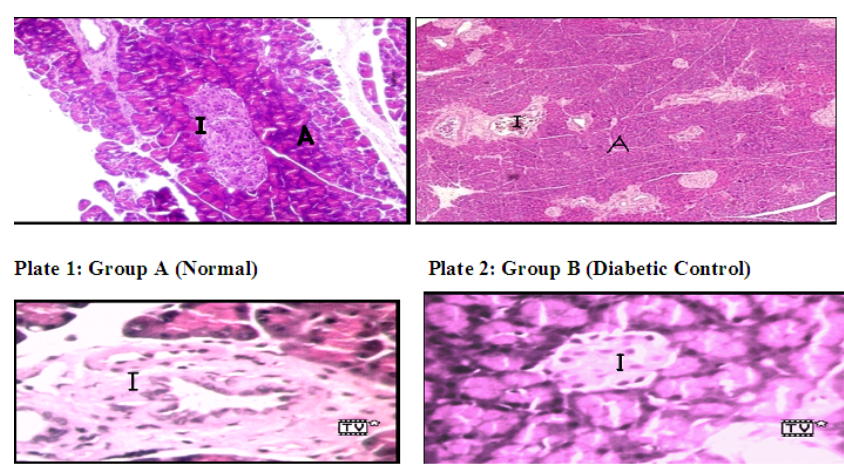

Plate 2: Group B (Diabetic Control)

Plate 3: Group C (Pioglitazone)

Plate 4: Group D (Spirulina)

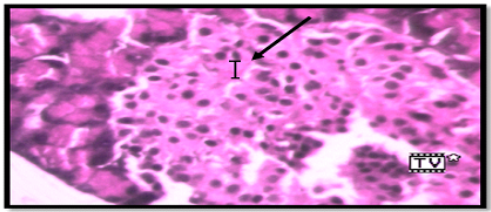

Plate 5: Group E (Pioglitazone with Spirulina)

Figure 1: Photomicrograph of pancreas stained with haemotoxylin and eosin (H \& E) (magnification 200x)
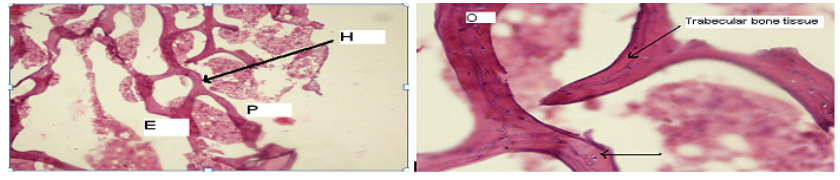

Plate 1: Group A (Normal)
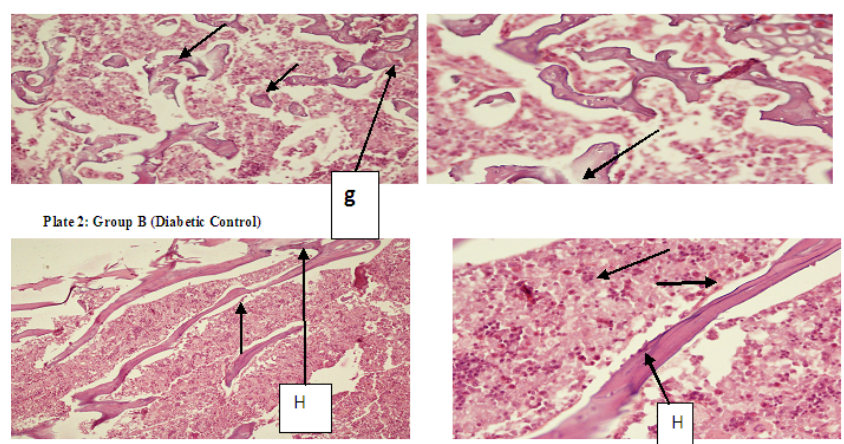

Plate 3: Group C (Pioglitazone)
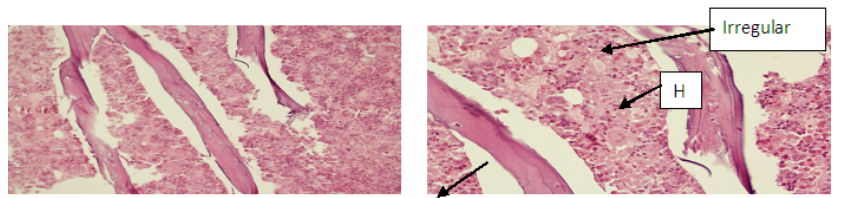

Plate 4: Group D(Spirulina)
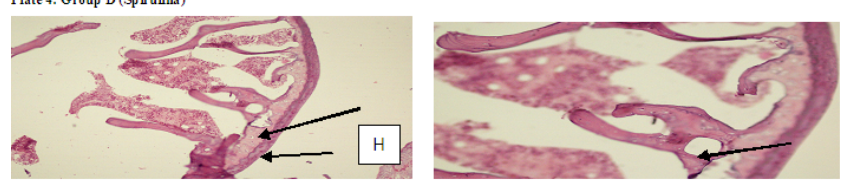

Plate 5: Group E (Pioglitazone with Spir ulina)

Figure 2: Photomicrograph of the middle shaft of the femur bone stained with haemotoxylin and eosin (H\& E) (magnification 100x and 200x). 


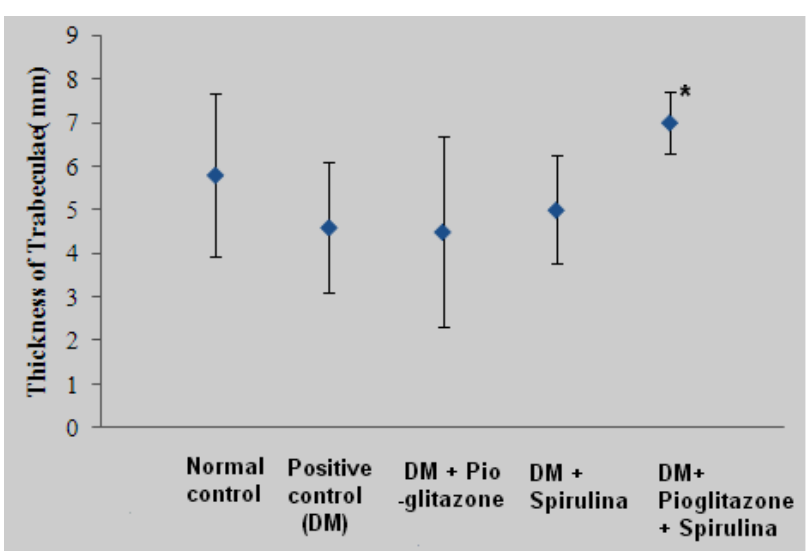

Figure 3: Effect of Pioglitazone and Spirulina on trabeculae thickness of bone tissue after 45 days treatment in dexamethasone rat model.

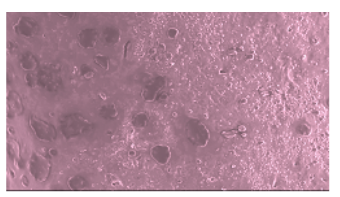

a: Normal group

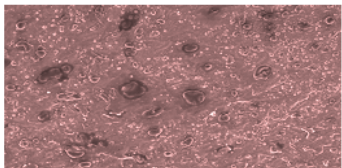

c: Pioglitazone treated group

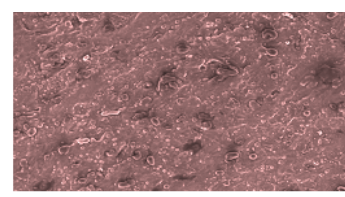

b: Diabetic control group

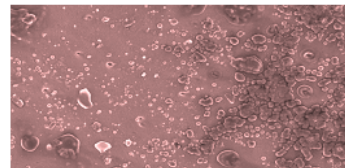

d: Pioglitazone with Spirulina
Figure 4: Scanning Electron Microscopy under (500x) of right femur bone in different groups (Dexamethasone rat model).

Spirulina and Pioglitazone treated alone group with, the results showed statistical non-significant as shown in Figure 3.

The SEM picture showed that group pioglitazone rats (Figure 4c) treatment increased the number of resorptive pits per every square centimeter when compared to group diabetic mellitus rats (DM) (Figure 4b). Spirulina treatment along with pioglitazone reduced the osteoporotic effect of pioglitazone (Figure 4d) and improved the intactness and integrity of the bone surface compared to normal group (Figure 4a).

\section{Discussion}

Clinically, the patients with type 2 diabetes are characterized by the change of insulin secretion and/or insulin action. Also, insulin resistance is another serious problem in clinic. Insulin resistant animal model induced by dexamethasone injection causes type 2 diabetes [20] as that in clinic, change of insulin action seems more important than the alternation of insulin secretion. Defects in the insulin-signaling pathway, owing to mutations in the insulin receptor gene, the presence of antibodies to the insulin receptor or insulin itself are some of the factor responsible for insulin resistance. Dexamethasone causes insulin resistance as measured by several markers, including a reduction in insulin-stimulated glucose uptake and a decrease in glucose oxidation.
While the precise cause or causes are not yet known, it is accepted that dexamethasone affects insulin signaling at several levels [27]. In addition to this, insulin resistance is also major risk factor for fracture of bone for skeletal health [28] Pioglitazone is a thiazolidinedione derivative as anti-diabetic agent. The mechanism of action of glitazone involves activation of Peroxisome Proliferators-Activated ReceptorGamma, (PPAR- $\gamma$ ) which helps to modulate the transcription of a number of insulin responsive genes involved in the control of glucose and lipid metabolism [29]. Recently two studies reported on long term usage of pioglitazone in diabetic patients showed the risk of incident cancer at the 10 most common sites namely, prostate, female breast, lung/bronchus, endometrial, colon, non-hodgkin lymphoma, pancreas, kidney/renal pelvis, rectal melanoma [30] and bladder cancer [31] but it was no clear evidence the association between use of pioglitazone and risk of cancer due to lack of information is available (smoking \& occupational risks) [32]. European medicines agency [15] alert that the risk factors for bladder cancer should be investigate particularly in elderly patients and prescribers are advised to carefully select patients and monitor how they respond to treatment. In addition to this, glitazone administration $(10 \mathrm{mg} / \mathrm{kg})$ results in significant bone loss due to sensitized PPAR- $\gamma 2$ isoforms, which is critical for the regulation of osteoblast and adipocytes differentiation.

Spirulina has been labeled as a powerful food, rich in proteins, carbohydrates, polyunsaturated fatty acids, sterols and some more vital elements like calcium, chromium, iron, zinc, magnesium, manganese and selenium. It is a natural source of vitamin $B_{12}$, vitamin $E$, ascorbic acid, tocopherols and whole spectrum of natural mixed carotene and xanthophylls phytopigments [33-35].

In dexamethasone induced insulin resistance model, Pioglitazone with spirulina treatment showed statistically significant change in reducing both hyperglycemia and lipid level (Table 1,2$)(\mathrm{p}<0.001)$. The presence of chromium in Spirulina makes it a highly beneficial adjuvant therapy [18]. Chromium binds to peptide known as ApoLMWCr that in turn binds to insulin receptor and enhances the activity [36]. Oral administration of Spirulina with Pioglitazone and Spirulina alone reversed the morphological changes of pancreas after induction of dexamethasone which shows the recovery of partially destroyed $\beta$-cells, cell size back to the normal position, increases the $\beta$-cells and preventing the death of $\beta$-cells which clearly demonstrated the protective effects of spirulina on Pancreas. This was clearly demonstrated as the levels of insulin reverted back to normal in diabetic rats treated with Spirulina (Table 3). Pioglitazone and Pioglitazone with Spirulina treated groups decreased the LDL and TGs levels significantly $(\mathrm{P}<$ 0.0001) compared to diabetic control group. Earlier studies have shown that PPAR- $\gamma$ activation in hepatocytes and enhanced lipoprotein lipase due to insulin sensitivity helps in reducing LDL and TG levels [37,38]. Keeping in view the pharmacological properties of Spirulina fusiformis, present investigation was undertaken to assess the protective effect of S. fusiformis extract against Pioglitazone induced osteoporosis and also investigates the pharmacodynamics effects of Pioglitazone with Spirulina in treating hyperglycemia and hyperlipidemia in insulin resistance rats.

Insulin plays a significant role in bone health in diabetes [39]. IGF-I and insulin receptor are reduced implying dysregulation of the IGF action on bone in the diabetic state $[40,41]$. It has been suggested that diabetes can revert osteoblast into reticent bone-lining cells. This is supported by studies showing that the diabetic state influences infiltrating cells in a marrow ablation model to behave as immature mesenchymal cells due to altered gene expression of prosoteoblastic proteins [42]. 
In the present study, the histopathology results in middle shaft of femur bone of a insulin resistance rat showed destruction of medullary cavity at the expense of the bone tissue thickness and gaps formation in Haversian canals within the bone tissue. In Pioglitazone with Spirulina treated group, the results demonstrated that the trabeculae bone thickness returned into original position to decrease the risk fracture. Observation in the trabeculae thickness on the surface of the bone clearly shows that spirulina improved the intactness and integrity of the bone surface possibly due to its ability to stimulate mineral absorption by intestinal micro flora. The decreased porosity caused by insensitivity of insulin receptor and activated PPAR- $\gamma 2$ functions as a dominant negative regulator of osteoblast differentiation [18] is substantially treated with spirulina, which in turn causes remineralization of bones.

The second probable mechanism is that direct link exists between insulin action and bone formation. The IR is a tyrosine kinase receptor and signals intracellularly through insulin receptor substrate molecules, IRS1 to IRS-4, that result in unique bone formation phenotype over bone resorption, whereas as IRS-1 regulates bone turn over. In addition to the direct effect of insulin on osteoblasts bone cells, it may exert synergistic effects with other anabolic agents in bone, such as IGF-I and parathyroid hormone. IG-FBP-1 is acutely down regulated by insulin in a variety of tissues and is similarly suppressed by insulin in bone cells $[43,44]$. The third probable mechanism suggests that insulin inactivate p27, a cyclin-dependent kinase inhibitor that could attenuate cell proliferation in osteoblasts [45-47]. With addition to this, adiponectin is one of the recent attracted widespread attentions in diabetic osteoporosis. One of the possible mechanism involved osteoblasts have an adiponectin stimulates osteoblastogenesis and bone formation in cultures osteoblasts which regulates bone turnover via enhancing the receptor activator of nuclear factor- $\mathrm{kB}$ ligand expression and suppressing decoy receptor, osteoprotegerin [48]. The anti-diabetic activity may be partly mediated by stimulatory effects on signaling pathways for 5 ' adenosine monophosphate-activated protein kinase and peroxisome proliferator activated receptor a [49]. This present report for the first time demonstrated the unique protective activity of spirulina on histomorphological changes in dexamethasone induced osteoporosis in Pioglitazone treated rats. The results of the pharmacodynamics interaction of spirulina on Pioglitazone have shown synergistic effects on the anti-diabetic and anti-osteoporosis properties of both these drugs.

The present study clearly demonstrates the efficacy of using spirulina extract to prevent effect of dexamethasone induced increase in bone turnover rate and to restore the loss of trabecular bone mass in Pioglitazone treated rats. Finally, it is concluded that Spirulina therapy will be highly beneficial in reducing the risk fracture of bone in Pioglitazone treated dexamethasone induced diabetic rats.

\section{Acknowledgements}

The authors are grateful to management for offering the requisite technical help to accomplish this study. A word of gratitude to Recon Limited, Bangalore for providing Spirulina fusiformis and to Torrent Pharmaceutical Ltd, Ahmedabad for donating Pioglitazone malleate. The authors acknowledge the excellent technical work under Dr. B.N Dutta providing the histopathology microscopy facility, Department of Biochemistry and Pathology lab, P.G.I, Chandigarh. The authors gratefully acknowledge the colleagues for encouraging and providing the necessary research facilities to conduct this study. There was no funding from any outside agency.

\section{References}

1. Enayat AO, Nermeen MS, Sayed AET, Wafaa AA (2009) Histomorphometric evaluation of bone tissue exposed to experimental osteoporosis and treated with Retama Raetam extract. Journal of Applied Sciences Research 5: 706716

2. Thrailkill KM, Lumpkin CK, Bunn RC, Kemp SF, Fowlkes JL (2005) Is insulin an anabolic agent in bone? Dissecting the diabetic bone for clues. Am J Physio Endocrinol Metab 289: E735-E745.

3. Schwartz AV, Sellmeyer DE, Strotmeyer ES, Tylavsky FA, Feingold KR, et al (2005) Diabetes and bone loss at the hip in older black and white adults. J Bone Miner Res 20: 596-603.

4. Siris ES, Miller PD, Barrett-Connor E, Faulkner KG, Wehren LE, et al. (2001) Identification and fracture outcomes of undiagnosed low bone mineral density in postmenopausal women: results from the National Osteoporosis Risk Assessment. JAMA 286: 2815-2822.

5. Harris M, Nguyen TV, Howard GM, Kelly PJ, Eisman JA (1998) Genetic and environmental correlations between bone formation and bone mineral density: a twin study. Bone 22: 141-145.

6. Recker RR, Deng HW (2002) Role of genetics in osteoporosis. Endocrine 17: 55-66.

7. Eisman JA (1999) Genetics of osteoporosis. Endocr Rev 20: 788-804

8. Isaia GC, Ardissone P, Di Stefano M, Ferrari D, Martina V, et al. (1999) Bone metabolism in type 2 diabetes mellitus. Acta Diabetol 36: 35-38.

9. Krakauer JC, McKenna MJ, Buderer NF, Rao DS, Whitehouse FW, et al. (1995) Bone loss and bone turnover in diabetes. Diabetes 44: 775-782.

10. Nathan DM, Buse JB, Davidson MB, Ferrannini E, Holman RR, et al. (2009) Medical management of hyperglycemia in type 2 diabetes: a consensus algorithm for the initiation and adjustment of therapy: a consensus statement of the American Diabetes Association and the European Association for the Study of Diabetes. Diabetes Care 32: 193-203.

11. Schwartz AV, Sellmeyer DE, Vittinghoff E, Palermo L, Lecka-Czernik B, et al. (2006) Thiazolidinedione use and bone loss in older diabetic adults. J Clin Endocrinol Metab 91: 3349-3354.

12. Derosa G, CiCero AF, Gaddi A, Ragonesi PD, Piccinni MN, et al. (2005) A comparison of the effects of pioglitazone and rosiglitazone combined with glimepiride on prothrombotic state in type 2 diabetic patients with the metabolic syndrome. Diabetes Res Clin Pract 69: 5-13

13. Panigrahy D, Huang S, Kieran MW, Kaipainen A (2005) PPARgamma as a therapeutic target for tumor angiogenesis and metastasis. Cancer Biol Ther 4: 687-693.

14. Monami M, Lamanna C, Marchionni N, Mannucci E (2008) Rosiglitazone and risk of cancer: a meta-analysis of randomized clinical trials. Diabetes Care 31 1455-1460.

15. www.ema.europa.eu

16. Day C (1999) Thiazolidinediones: A new class of anti-diabetic drugs. Diabet Med 16: 179-192.

17. Rzonca SO, Suva LJ, Gaddy D, Montague DC, Lecka-Czernik B (2004) Bone is a target for the anti-diabetic compound Rosiglitazone. Endocrinology 145 : 401-406.

18. Gupta S, Hrishikeshvan HJ, Sehajpal PK (2010) Spirulina protects against Rosiglitazone induced osteoporosis in insulin resistance rats. Diabetes Res Clin Pract 87: 38-43.

19. Ishimi Y, Sugiyama F, Ezaki J, Fujioka M, Wu J (2006) Effects of spirulina, a blue green alga, on bone metabolism in ovariectomized rats and hindlimbunloaded mice. Biosci Biotechnol Biochem 70: 363-368.

20. Shalam MD, Harish MS, Farhana SA (2006) Prevention of Dexamethasone and fructose induced insulin resistance in rats by SH-01D a herbal preparation. Ind J Pharmacol 38: 419-422.

21. Giordano BP, Thrash W, Hollenbaugh L, Dube WP, Hodges C, et al. (1989) Performance of seven blood glucose testing systems at high altitude. Diabetes Educ 15: 444-448.

22. Kaur G, Kulkarni S (2000) Antiobesity effect of a polyherbal formulation, OB$200 \mathrm{G}$ in female rats fed on cafeteria and atherogenic diets. Indian J Pharmaco 32: 294-299.

23. Allain CC, Poon LS, Chan CS, Richmond W, Fu PC (1974) Enzymatic determination of total serum cholesterol. Clin Chem 20: 470-475.

24. Friedewald WT, Levy RI, Fredrickson DS (1972) Estimation of the concentration of low density lipoprotein cholesterol in plasma, without use of the preparative ultracentrifuge. Clin Chem 18: 499-502. 
Citation: Devesh C, Kritika M, Anroop N, Kumar SP, Sumeet G (2012) Spirulina Reverses Histomorphological Changes in Diabetic Osteoporosis in Pioglitazone Treated Rats. J Diabetes Metab S1:006. doi:10.4172/2155-6156.S1-006

25. Al-hasem F, Ibrahim I, Bastawy N (2011) Effect of insulin on adiponectin and adiponectin receptor-1 expression in rats with streptozotocin-induced type 2 diabetes. J Heath Sci 57: 334-340.

26. Stevens A (1982) The haematoxylins. In: Bancroft JD, Stevens A. Theory and practice of Histological Techniques. (London: Longman Group, 109-122).

27. Brunetti A, Goldfine ID (1995) Insulin receptor gene expression and insulin resistance. J Endocrinol Invest 18: 398-405.

28. Turnbow MA, Keller SR, Rice KM, Garner CW (1994) Dexamethasone downregulation of insulin receptor substrate-1 in 3T3-L-1 adipocytes. J Biol Chem 269: 2516-2520.

29. Strotmeyer ES, Cauley JA, Schwartz AV, Nevitt MC, Resnick HE, et al. (2004) Diabetes is associated independently of body composition with BMD and bone volume in older white and black men and women: The Health, Aging and body composition study. J Bone Miner Res 19: 1084-1091.

30. Ferrara A, Lewis JD, Quesenberry CP, Peng T, Strom BL, et al. (2011) Cohort study of pioglitazone and cancer incidence in patients with diabetes. Diabetes care 34: 923-929.

31. Lewis JD, Ferrara A, Peng T, Hedderson M, Bilker WB, et al. (2011) Risk of bladder cancer among diabetic patients treated with pioglitazone: interim report of a longitudinal cohort study. Diabetes care 34: 916-922.

32. Piccinni C, Motola D, Marchesini G, Poluzzi E (2011) Assessing the association of pioglitazone use and bladder cancer through drug adverse event reporting. Diabetes care 34: 1369-1371.

33. Ojiakoi OA, Nwanjo HU (2005) Effects of pioglitazone on atherogenic risk predictor indices of alloxan-induced diabetic rabbits. Biokemistri 17: 179-184.

34. Chamorro G, Salazar M, Favila L, Bourges H (1996) Pharmacology and toxicology of Spirulina alga. Rev Invest Clin 48: 389-399.

35. Chamorro G, Salazar M, Araújo KG, dos Santos CP, Ceballos G, et al. (2002) Update on the pharmacology of Spirulina (Arthrospira), an unconventional food. Arch Latinoam Nutr 52: 232-240.

36. Piñero Estrada JE, Bermejo Bescós P, Villar del Fresno AM (2001) Antioxidant activity of different fractions of spirulina platensis protean extract. Farmaco 56: 497-500.

37. Vincet JB (2000) The Biochemistry of Chromium. J Nutr 130: 715-718.
38. Parikh $P$, Mani $U$, lyer $U$ (2001) Role of spirulina in the control of glycemia and lipidemia in type 2 diabetes mellitus. J Med Food 4: 193-199.

39. Torres-Duran PV, Ferreira-Hermosillo A, Juarez-Oropeza MA (2007) Antihyperlipedemic and antihypertensive effects of spirulina maxima in an open sample of Mexican population: a preliminary report. Lipids Health Dis 6: 33.

40. Fukunaga Y, Minamikawa J, Inoue D, Koshiyama H (1997) Does insulin use increase bone mineral density in patients with non-insulin dependent diabetes mellitus? Arch Intern Med 157: 2668-2669.

41. Maor G, Karnieli E (1999) The Insulin -sensitive glucose transporter (GLUT4) is involved in early bone growth in control and diabetic mice, but is regulated through the insulin -like growth factor I receptor. Endocrinology 140: 1841-1851.

42. Paul RG, Bailey AJ (1996) Glycation of collagen: the basis of its central role in the late complications of ageing and diabetes. Int J Biochem Cell Biol 28 : 1297-1310.

43. Akune T, Ogata N, Hoshi K, Kubota N, Terauchi Y, et al. (2002) Insulin recepto substrate-2 maintains predominance of anabolic function over catabolic function of osteoblasts. J Cell Biol 159: 147-156.

44. Verhaeghe J, Suiker AM, Nyomba BL, Visser WJ, Einhorn TA, et al. (1989) Bone mineral homeostasis in spontaneous diabetic BB rats. II. Impaired bone turnover and decreased osteocalcin synthesis. Endocrinology 124: 573-582.

45. Lu H, Kraut D, Gerstenfeld LC, Graves DT (2003) Diabetic interferes with the bone formation by affecting the expression of transcription factors that regulates osteoblast differentiation. Endocrinology 144: 346-352.

46. Ogata N, Chikazu D, Kubota N, Terauchi Y, Tobe K, et al. (2000) Insulin recepto substrate-1 in osteoblast is indispensable for maintaining bone turnover. J Clin Invest 105: 935-943.

47. Uchida, T, Nakamura T, Hashimoto N, Matsuda T, Kotani K, et al. (2005) Deletion of Cdkn1b ameliorates hyperglycemia by maintaining compensatory hyperinsulinemia in diabetic mice. Nat Med 11: 175-182.

48. Kanazawa I, Yamaguchi T, Yamamoto M, Yamauchi M, Yano S, et al. (2009) Relationships between serum adiponectin levels versus bone mineral density, bone metabolic markers and vertebral fractures in type 2 diabetes mellitus. Eur J Endocrinol 160: 265-273.

49. Li S, Shin HJ, Ding EL, van Dam RM (2009) Adiponectin levels and risk of type 2 diabetes a systematic review and meta-analysis. JAMA 302: 179-188.
This article was originally published in a special issue, Diabetic Osteoporosis handled by Editor(s). Dr. Laura McCabe, Michigan State University, USA 